\title{
Minimally Invasive Resection of Large Gastric Gastrointestinal Stromal Tumors
}

\author{
Emma C. Gertsen ${ }^{a}$ Gijs I. van Boxel ${ }^{a}$ Lodewijk A.A. Brosens $^{b}$ Jelle P. Ruurda ${ }^{a}$ \\ Richard van Hillegersberg ${ }^{a}$ \\ aDepartment of Surgery, University Medical Center Utrecht, Utrecht University, Utrecht, The Netherlands; \\ ${ }^{b}$ Department of Pathology, University Medical Center Utrecht, Utrecht University, Utrecht, The Netherlands
}

\author{
Keywords \\ Gastrointestinal stromal tumors · Laparoscopic surgery · \\ Morbidity · Cohort study
}

\begin{abstract}
Introduction: Gastrointestinal stromal tumors (GISTs) frequently present as a large exophytically growing mass in the stomach, for which open partial gastrectomy is standard of care. The aim of this study was to evaluate the safety and feasibility of minimally invasive gastric resection (MIG) of large (>5 cm) GIST. Methods: All patients who underwent MIG for a GIST in the University Medical Center Utrecht between 2011 and 2019 were included. Postoperative course and oncological outcomes were analyzed. Results: Twentytwo patients with gastric GIST, median size $53 \mathrm{~mm}$ [20-175 $\mathrm{mm}$ ], underwent MIG. In 4 patients, preoperative imatinib was given, aiming for tumor regression. Conversion from laparoscopic to open surgery occurred once (5\%). An additional resection was performed in 3 patients (14\%). In 2 patients (9\%), an intraoperative complication occurred, consisting of tumor rupture in 1 patient (5\%), and 6 patients (27\%) developed postoperative complications. Median hospital stay was 5 days [3-7 days]. R0 resection was achieved in $96 \%$. In 4 patients, adjuvant treatment was indicated. The median follow-up was 31 months, and 1-, 3- and 5-year disease-free survival were 94,74 and $74 \%$, respectively. One pa-
\end{abstract}

karger@karger.com www.karger.com/dsu

Karger $\stackrel{\text { ' }}{5}$

GOPEN ACCESS
(C) 2020 The Author(s)

Published by S. Karger AG, Basel

This is an Open Access article licensed under the Creative Commons Attribution-NonCommercial-4.0 International License (CC BY-NC) (http://www.karger.com/Services/OpenAccessLicense), applicable to the online version of the article only. Usage and distribution for commercial purposes requires written permission. tient presented with local recurrence 2 years after the index resection. Conclusion: MIG for large GIST up to $17.5 \mathrm{~cm}$ in diameter is safe, feasible, and oncologically sound, allowing for a controlled resection and reduced patient morbidity.

(C) 2020 The Author(s)

Published by S. Karger AG, Basel

\section{Introduction}

Gastrointestinal stromal tumors (GISTs) are the most common type of mesenchymal tumors in the gastrointestinal tract [1] and most frequently occur in the stomach (50-60\%), followed by the small intestines (20-30\%) and rectum (10\%) [2]. In the Netherlands, gastric GIST has had an annual incidence of 130 cases for the entire population (17 million) but appears to be increasing [3]. Radical surgical resection with prevention of rupture is the cornerstone of curative treatment for GIST $\geq 2 \mathrm{~cm}[4,5]$.

Minimally invasive gastric surgery (MIG) has gained popularity in surgical oncology since it embraces benefits such as reduced postoperative morbidity and shorter length of hospital stay $[6,7]$. In addition, since MIG appears to cause less operative trauma compared to traditional open surgery, more frail patients may be considered for resection. However, previously reported contraindications for MIG are tumor size, invasion into adjacent organs, and a tumor near the gastroesophageal

Richard van Hillegersberg

Division Cancer Center, Department of Surgery, University Medical Center Utrecht Heidelberglaan 100

NL-3584 Utrecht (The Netherlands)

R.vanHillegersberg@umcutrecht.nl 
junction $[1,8]$. Opinions differ on whether MIG is feasible and safe for "large" GIST (those exceeding $5 \mathrm{~cm}$ in size). To date, guidelines advise that GIST exceeding $5 \mathrm{~cm}$ in size should only be treated by open resection [5]. Few studies report on laparoscopic resection being superior to open surgery for gastric GIST [1, 9-11]. However, most of these studies were conducted in an Asian population with different patient and tumor characteristics, such as lower BMI and smaller sized tumors, compared to the Western population. Consequently, the aim of this study was to evaluate the safety and feasibility of MIG for large gastric GIST in a Western population.

\section{Materials and Methods}

\section{Study Population}

This descriptive, single-center, retrospective study included all patients who underwent MIG for a GIST between January 2011 and December 2019 from the University Medical Center Utrecht (UMC Utrecht). In the regional Comprehensive Cancer Network Utrecht (population: 1.2 million), surgical treatment of upper gastrointestinal tumors is centralized in the UMC Utrecht, and approximately 130 upper gastrointestinal cancer patients are operated annually, varying from wedge resections of GIST to robotassisted minimally invasive thoracolaparoscopic esophagectomy. Since 2006, MIG is the standard procedure for gastric GIST in the UMC Utrecht.

Patients were diagnosed via gastroscopy with biopsies or EUS with fine needle aspiration and $\mathrm{CT}$ of the thorax and abdomen. If indicated, preoperative treatment with imatinib was given, and surgical wedge resection or partial gastrectomy was performed. No lymphadenectomy was performed, since gastric GISTs have a very low risk of dissemination to the lymph nodes $[1,5,8,9]$. Data on all upper gastrointestinal procedures were prospectively registered in the Upper-GI database of the Department of Surgery. The resection specimens were collected from the pathology archives and reevaluated by an experienced gastrointestinal pathologist (L.A.A.B.) to reassess pathological characteristics. In case of a high-grade tumors with high risk of progressive disease according to the NCCN Guidelines, adjuvant imatinib was given [5]. According to the Medical Ethical Committee and the Medical Research Involving $\mathrm{Hu}$ man Subjects Act (WMO), informed consent requirement was waived.

\section{Surgical Techniques}

All patients were positioned in the supine position. A 12-mm balloon trocar was placed and 4 additional ports were used: 2 working ports (each $5 \mathrm{~mm}$ ), an assisting port $(5 \mathrm{~mm})$, and a port through which the liver retractor could be introduced $(12 \mathrm{~mm})$. The lesser omentum was opened. Then, the tumor was located and approached carefully, and in case of a dorsally located tumor, the bursa was opened through the gastrocolic ligament. As preservation of the vagus nerve is important to achieve good functional outcome, these were preserved. If a wedge excision was sufficient, a local resection of the tumor was performed, using a barbed suture to close the defect anatomically. In case no hand-sewn anatomical
Table 1. Baseline characteristics of the patients who underwent minimally invasive surgery for gastrointestinal stromal cell tumor

\begin{tabular}{lc}
\hline & GIST $n=22(\%)$ \\
\hline Age, years (mean \pm SD) & $70.4 \pm 10.0$ \\
BMI, kg/m² (mean \pm SD) & $27.9 \pm 5.5$ \\
Gender (female, $\%)$ & $13(59)$ \\
ASA classification & \\
I & $0(0)$ \\
II & $13(62)$ \\
III & $7(33)$ \\
IV & $1(5)$ \\
Comorbidities & $9(41)$ \\
Cardiac & $11(50)$ \\
Vascular & $3(14)$ \\
Diabetes & $3(14)$ \\
Pulmonary & $19(86)$ \\
c-KIT expression & $4(18)$ \\
Neoadjuvant treatment & \\
Yes (imatinib) & \\
\hline
\end{tabular}

Percentages may not add up to $100 \%$ due to rounding. ASA, American Society of Anesthesiologists.

reconstruction could be performed (e.g., in case of a tumor near the gastroesophageal junction), the EndoGIA $(60 \mathrm{~mm})$ was used to perform the wedge resection. In case of a tumor location near the gastroesophageal junction, a gastroduodenoscopy was used intraoperatively to assess the patency and diameter of the lumen. If a partial gastrectomy was necessary, this was performed laparoscopically as described previously [12]. The resected specimen was removed through a mini-laparotomy, which was intraoperatively infiltrated with bupivacaine and located according to the surgeon's insight. A ring wound retractor that enlarges the wound was used to extract large tumors. If required, a Roux-en-Y gastroenterostomy was created. Supplementary file (see online suppl. 1; see www.karger.com/doi/10.1159/000510386 for all online suppl. material) demonstrates a video of a minimally invasive partial gastrectomy for a large GIST $(13.9 \times 8.6 \mathrm{~cm})$.

\section{Study Outcomes}

Patient and tumor characteristics, intraoperative surgical parameters, postoperative outcomes, histopathological characteristics, and follow-up were prospectively collected and assessed (Tables 1-5).

\section{Results}

\section{Study Population}

Between 2011 and 2019, 22 consecutive patients underwent surgical gastric resection for a GIST. The mean age was 70.4 years, and mean BMI was $27.9 \mathrm{~kg} / \mathrm{m}^{2}$ (Table 1). Most of the patients were female (59\%) and had an ASA II classification, where cardiac and vascular comor- 
Table 2. Surgical characteristics of the patients who underwent minimally invasive surgery for gastrointestinal stromal cell tumor

\begin{tabular}{lc}
\hline & GIST $n=22(\%)$ \\
\hline Conversion & $1(5)$ \\
Type of resection & \\
$\quad$ Partial gastrectomy & a \\
$\quad$ Wedge & $3(14)$ \\
Additional resection & $19(86)$ \\
$\quad$ Diaphragm + spleen & $3(14)$ \\
Spleen + pancreas & $1(5)$ \\
$\quad$ Meso)Colon & $1(5)$ \\
Cruroplasty & $1(5)$ \\
Operation time (min; mean \pm SD) & $2(9)$ \\
Operation time (min; median, IQR) & $107(48)$ \\
Intraoperative complication & $103[72-138]$ \\
$\quad$ Bowel injury & $3(14)$ \\
Spill due to tumor rupture & $2(9)$ \\
\hline
\end{tabular}

Percentages may not add up to $100 \%$ due to rounding. ${ }^{\text {a }}$ In all patients, a gastroenterostomy was created.

bidities were most common (both accounting for almost $50 \%)$. c-KIT expression was found in the biopsies of 19 patients (86\%), and 4 patients received preoperative imatinib. In 2 patients, the effect of preoperative imatinib on the tumor was objectively assessed by a re-staging CT abdomen, which showed a size reduction to $9.2 \mathrm{~cm}$ in 1 patient (original size $13.9 \mathrm{~cm}$ ) and to $2.0 \mathrm{~cm}$ in another patient (original size $7.0 \mathrm{~cm}$ ). In the other 2 patients, persistent bleedings occurred during imatinib treatment, resulting in resection before completion of the imatinib.

\section{Intraoperative Parameters}

Intraoperative parameters are shown in Table 2. The majority of patients underwent a wedge resection (86\%). In case of partial gastrectomy (3 patients, $14 \%$ ), a gastrojejunostomy was created. Conversion from laparoscopic to open surgery occurred in 1 patient, due to invasion of the GIST in the pancreas and spleen, resulting in an additional partial resection of the pancreas and splenectomy. In another 2 patients, an additional resection was performed beyond the GIST to ensure en bloc oncological resection: resection of diaphragm and an edge of the spleen and resection of part of the transverse mesocolon. All additional resections took place during the index operation. A cruroplasty was performed intraoperatively in 2 patients (9\%). In 3 patients (14\%), an intraoperative complication occurred: in 2 patients, a bowel injury occurred (requiring suturing), and in 1 patient, who was operated in an emergency setting because of bleeding, a
Table 3. Postoperative outcomes of the patients who underwent minimally invasive surgery for gastrointestinal stromal cell tumor

\begin{tabular}{ll}
\hline & GIST $n=22(\%)$ \\
\hline $\begin{array}{ll}\text { Morbidity } \\
\text { Intra-abdominal complications }\end{array}$ & $6(27)$ \\
Anastomotic leakage & \\
Perforation at suturing site $_{\text {Abscess }}$ & $0(0)$ \\
Bleeding & $1(5)$ \\
Pancreatitis, leakage or fistula & $0(0)$ \\
Chyle leakage & $0(0)$ \\
Trauma of the gut & $0(0)$ \\
Gastroparesis & $0(0)$ \\
Wound complications & $0(0)$ \\
Non-surgical complications & $0(0)$ \\
Pulmonary & $0(0)$ \\
Cardiac & \\
Thromboembolic & d \\
Neurologic & \\
Urologic &
\end{tabular}

Percentages may not add up to $100 \%$ due to rounding. ICU, Intensive Care Unit; IQR, interquartile range. ${ }^{\text {a }}$ Any clinically or radiologically proven anastomotic leakage. ${ }^{\mathrm{b}}$ Pneumonia, pleural effusion, respiratory failure, pneumothorax, and/or acute respiratory distress syndrome (ARDS). ' Supraventricular arrhythmia, myocardial infarction, and/or heart failure. ${ }^{\mathrm{d}}$ Pulmonary embolism, deep venous thrombosis, and/or cerebrovascular accident. ${ }^{\mathrm{e}}$ Acute delirium. ${ }^{\mathrm{f}}$ Acute renal insufficiency, acute kidney failure requiring dialysis, urinary tract infection, and/or urine retention. ${ }^{g}$ Patient in whom conversion from minimally invasive to open surgery took place.

small tumor perforation occurred at extraction, without spill (macroscopically no tumor was left behind). The mean overall operating time was $107 \mathrm{~min}$.

\section{Postoperative Outcomes}

In total, 6 patients (27\%) developed postoperative complications (Table 3). In 1 patient, a re-operation was needed with surgical drainage and repair of a leakage at the sutured defect following a wedge resection. In this patient, the defect was located near the pylorus at the lesser curve and closed with a barbed suture. Two patients developed a hospitalacquired pneumonia, 1 patient had cardiac complications (supraventricular fibrillation combined with a troponin 
Table 4. Histopathological characteristics of the patients who underwent minimally invasive surgery for gastrointestinal stromal cell tumor

\begin{tabular}{|c|c|}
\hline & GIST $n=22(\%)$ \\
\hline Size $(\mathrm{mm} ;$ mean $\pm \mathrm{SD})$ & $57(35)$ \\
\hline Size (mm; median, ranges) & $53(20-175)$ \\
\hline Size $>5 \mathrm{~cm}$ & $12(55)$ \\
\hline Mitotic rate $\leq 5 / 5 \mathrm{~mm}^{2 \mathrm{a}}$ & $17(77)$ \\
\hline \multicolumn{2}{|l|}{ Risk of progressive disease $\mathrm{b}^{\mathrm{b}}$} \\
\hline Low risk (WHO I, II, IIIa-IV) & $15(68)$ \\
\hline Moderate risk (WHO IIIb, V) & $2(9)$ \\
\hline High risk (WHO VIa-VIb) & $5(23)$ \\
\hline c-Kit mutation analysis & $9(41)$ \\
\hline \multicolumn{2}{|l|}{ Radicality of the resection } \\
\hline R0 & $21(96)$ \\
\hline $\mathrm{R} 1$ & $1(5)$ \\
\hline Lymph node resection $(y e s, \%)^{\mathrm{c}}$ & $5(23)$ \\
\hline Lymph node yield (median, IQR) & $2[2-11]$ \\
\hline Positive lymph nodes (median, IQR) & $0[0-0]$ \\
\hline
\end{tabular}

IQR, interquartile range. ${ }^{\text {a }}$ If a patient received preoperative treatment with Imatinib, it is questionable whether or not MAI count is reliable due to therapeutic changes (e.g., fibrosis) of the tumor. ${ }^{b}$ According to the NCCN Guidelines. ${ }^{c}$ The lymph nodes resected during the procedures were taken as part of the gastric resection. In none of the patients it was intentionally decided that lymphadenectomy was required.

Table 5. Follow-up data on the patients who underwent minimally invasive surgery for gastrointestinal stromal cell tumor

\begin{tabular}{lc}
\hline & GIST $n=22(\%)$ \\
\hline Stenosis & $0(0)$ \\
Adjuvant treatment & $4(18)$ \\
Follow-up (months; median, IQR) & $31[1-75]$ \\
Overall survival & \\
$\quad 1$ year & $94 \%$ \\
$\quad 3$ year & $86 \%$ \\
5 year & $86 \%$ \\
Recurrence & $1(5)$ \\
Disease-free survival & \\
$\quad 1$ year & $94 \%$ \\
3 year & $76 \%$ \\
5 year & $76 \%$ \\
\hline
\end{tabular}

IQR, interquartile range. ${ }^{\text {a }}$ Two years after surgery, patient presented with local recurrence with hepatogenic and peritoneal metastases.

rise), and 1 patient had a urologic complication (replacement of a bladder catheter due to retention). There was no postoperative mortality. Median ICU stay was $0[0-0]$ days and hospital stay was 5 days [3-7 days].

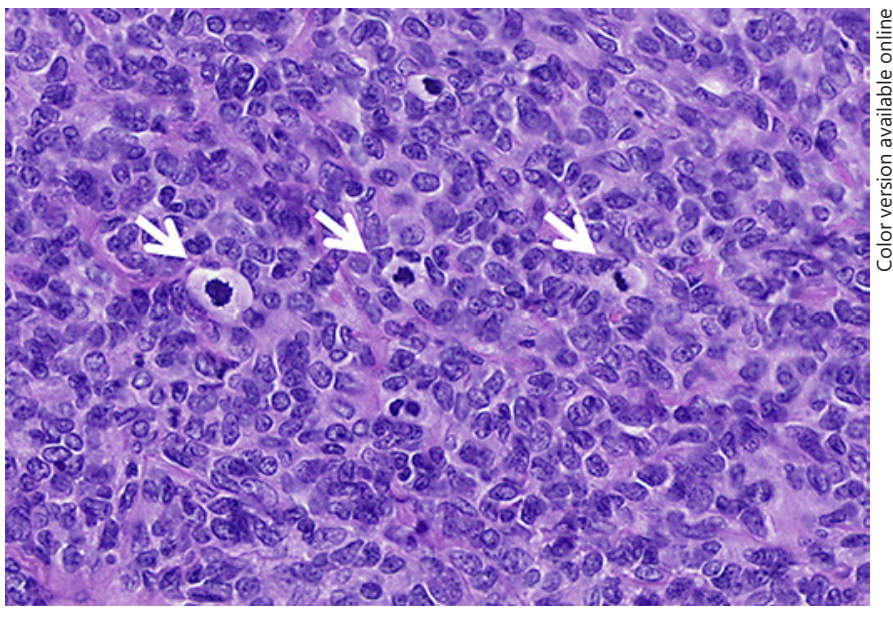

Fig. 1. Three mitoses per HPF in a patient with a high-grade GIST.

\section{Histopathological Outcomes}

Table 4 shows histopathological outcomes. The median size of the GIST was $53 \mathrm{~mm}$ (range $20-175 \mathrm{~mm}$ ), and mitotic rate was $\leq 5$ per $5 \mathrm{~mm}^{2}$ in the majority of patients (Fig. 1). Based on the WHO classification and Risk Stratification of Primary GIST by Mitotic Index, Size and Site table $[5,13], 15$ patients $(68 \%)$ had a low risk of progressive disease, 2 patients (9\%) had a moderate risk, and 5 patients $(23 \%)$ had a high risk of progressive disease. R0 resection was performed in all but 1 patient (96\%). In 1 patient with a dorsally located GIST, the tumor had a close relationship with the mesocolon and retroperitoneum. In this patient, tumor cells were found in the stapler edge, resulting in R1 resection. c-KIT expression was found in 19 patients (86\%) by immunohistochemistry. c-KIT mutation analysis was performed in 9 patients (41\%), of whom 4 patients were treated with preoperative imatinib.

\section{Follow-Up}

Table 5 summarizes follow-up data. Postoperative therapy with imatinib was administered in 4 patients (18\%, of whom 3 patients also received preoperative imatinib), as soon as this was permitted by the physical condition and postoperative recovery of the patient. The median follow-up was 31 months, and 1-, 3- and 5-year disease-free survival were 94,76 , and $76 \%$, respectively. Overall survival rates were 94,86 , and $86 \%(1,3$, and 5 years, respectively). To date, the patient in whom an R1 resection was performed did not present with recurrence. Two years after surgery, another patient presented with local recurrence with hepatogenic and peritoneal metastases. In this patient, with an initial tumor of $5.5 \mathrm{~cm}$, mitotic index of $>5$ mitoses per HPF, WHO risk category $6 \mathrm{a}$ 
and $\mathrm{R} 0$ resection, postoperative imatinib was stopped after 2 months due to toxicity. As yet, there are no patients with postoperative gastric stenosis.

\section{Discussion/Conclusion}

This study demonstrates that minimally invasive surgery for gastric GIST up to $17.5 \mathrm{~cm}$ in diameter can be performed safely and oncologically effective with excellent long-term results. In patients in whom an irresectable tumor with c-KIT expression is suspected, preoperative imatinib resulted in adequate tumor regression, allowing for MIG.

GISTs are the most common type of mesenchymal tumors in the gastrointestinal tract and require surgical resection once over $2 \mathrm{~cm}$, with clear margins because of its malignant potential. No lymphadenectomy is necessary due to the very low risk of dissemination to the lymph nodes $[1,5$, $8,9]$. Since the reports on improved patient outcomes following laparoscopic gastrectomy, MIG for GIST has gained popularity $[2,13,14]$. Several studies have reported on safety and feasibility of MIG for small gastric GIST [1, 8, 9, 15-19]. In addition to the safety and feasibility, MIG has many other benefits, as reviewed by Chen et al. [9]. In their systematic review and meta-analysis, 1,166 gastric GISTs were included, and benefits such as reduced blood loss, earlier first flatus day and oral intake, fewer postoperative complications, shorter hospitalization, and lower recurrence risk were described. Koh et al. [1] performed a similar study a year before with roughly the same results; however, the larger tumor size was mostly approached by open surgery.

Unfortunately, no systematic reviews or meta-analyses have been conducted for a Western population. De Vogelaere et al. [8] were one of the first to describe MIG for GIST in a Western population (31 patients) with a mean tumor size of $4.4 \mathrm{~cm}$ and range $0.4-11.0 \mathrm{~cm}$. A low morbidity rate was reported (1 patient [3.2\%] suffered from hemorrhage postoperatively) and no spill was reported [8]. Bischof et al. [19] performed a propensity score matched analysis on 248 Western patients with a mean tumor size of $3.9 \mathrm{~cm}$ (range $2.3-5.2 \mathrm{~cm}$ ) in the MIG group and found a postoperative grade $3+$ (Clavien-Dindo) morbidity rate of $3.2 \%$ in the MIG group and $13.7 \%$ in the open surgery group. They reported a spill rate of $1.6 \%$ during minimally invasive surgery and $0.8 \%$ during open surgery. A study by Melstrom et al. [17] also comparing laparoscopic versus open surgery for GIST in 17 patients with a mean tumor size of $4.3 \mathrm{~cm}$ (range 1.5-9.1 cm) reported $100 \%$ radical resections and $11.8 \%$ postoperative compli- cations. In the current study, much larger tumors (mean $5.7 \mathrm{~cm}$, range up to $17.5 \mathrm{~cm}$ ) in patients with less favorable characteristics (higher age and high BMI) could be treated laparoscopically. In this study, a higher number of patients required subtotal gastrectomy, which may explain the higher overall morbidity rate $(27 \%)$ and possibly higher rate of spill (5\%). Other Western studies report similar overall postoperative morbidity rates of $33 \%$, despite including younger patients with smaller tumors: $3.6 \mathrm{~cm}$ $(0.7-7.8 \mathrm{~cm})$ and $5.5 \mathrm{~cm}(2.5-12 \mathrm{~cm})[16,20]$.

In comparison with results from DeMatteo et al. [2], a higher R0 resection rate was found ( 81 vs. 96\%). Compared to De Vogelaere et al. [8], a shorter hospital stay (8.4 vs. 5 days) was found in the current study. Bischof et al. [19] and Melstrom et al. [17] reported a longer operation time (157 vs. 135 vs. $108 \mathrm{~min}$ in the current study). These differences might be caused by centralization of gastric cancer care in the Netherlands, starting of 2009, which results in more experienced surgeons in high-volume centers ( $>20$ gastrectomies per year per center required in the Netherlands).

The literature is scarce regarding long-term survival after MIG for large GIST. In the study of Karakousis et al., disease-free survival was $90 \%$, whereas Bischof et al. [19] reported a recurrence-free survival of $79.5 \%$ at the 5 -year follow-up. Likewise, the current study demonstrated a 5-year disease-free survival of $76 \%$.

Although this study has several strengths, such as the prospective data collection with complete data registry of patient and tumor characteristics, intra- and postoperative parameters (including recovery and follow-up data), and the preference for MIG regardless of the tumor size, a few limitations should be addressed. The current results are based on an observational study design and data of 2 experienced surgeons in a single university hospital; generalization of these results might therefore not be possible. In addition, the small sample size is potentially limiting.

In conclusion, MIG for large gastric GIST up to 17.5 $\mathrm{cm}$ in diameter is safe and feasible in a Western population with advanced GIST. The laparoscopic approach could be considered the standard of care for gastric GIST regardless of tumor size.

\section{Statement of Ethics}

All procedures followed were in accordance with the ethical standards of the responsible committee on human experimentation (institutional and national) and with the Helsinki Declaration of 1964 and later versions. This study does not fall within the Medical Research Involving Human Subjects Act (WMO), and informed consent requirement was waived. 


\section{Conflict of Interest Statement}

The authors have no conflicts of interest to declare.

\section{Funding Sources}

E.C.G., G.I.B., L.A.A.B., J.P.R., and R.H. declare that they have no financial ties to disclose.

\section{Author Contributions}

All authors have made substantial contributions to conceptualization, methodology, validation, formal analysis, investigation, resources, writing - original draft, writing - review and editing, visualization, and project administration. All authors have approved the submitted versions and have agreed both to be personally accountable for the author's own contributions and to ensure that questions related to the accuracy or integrity of any part of the work, even ones in which the author was not personally involved, are appropriately investigated, resolved, and the resolution documented in the literature.

\section{References}

1 Koh YX, Chok AY, Zheng HL, Tan CS, Chow $\mathrm{PK}$, Wong WK, et al. A systematic review and meta-analysis comparing laparoscopic versus open gastric resections for gastrointestinal stromal tumors of the stomach. Ann Surg Oncol. 2013;20(11):3549-60.

2 DeMatteo RP, Lewis JJ, Leung D, Mudan SS, Woodruff JM, Brennan MF. Two hundred gastrointestinal stromal tumors: recurrence patterns and prognostic factors for survival. Ann Surg. 2000;231(1):51-8.

3 Kankerregistratie $\mathrm{N}$. Incidence of gastric GISTs 2019: 2018-20. : https://www.cijfersoverkanker.nl/selecties/dataset_1/ img5d4ad3d3c3127? row $=1 \&$ direction $=$ up\#table.

4 Casali PG, Abecassis N, Bauer S, Biagini R, Bielack S, Bonvalot $S$, et al. Gastrointestinal stromal tumours: ESMO: EURACAN clinical practice guidelines for diagnosis, treatment clinical practice guidelines. Ann Oncol. 2018;29:68-78.

5 Demetri GD, Benjamin RS, Blanke CD, Blay JY, Casali P, Choi H, et al. NCCN Task Force report: management of patients with gastrointestinal stromal tumor (GIST): update of the NCCN clinical practice guidelines. J Natl Compr Canc Netw. 2007;5(Suppl 2):S1-29.

$6 \mathrm{Kim}$ W, Kim HH, Han SU, Kim MC, Hyung WJ, Ryu SW, et al. Decreased morbidity of laparoscopic distal gastrectomy compared with open distal gastrectomy for stage I gastric cancer: short-term outcomes from a multicenter randomized controlled trial (KLASS-01). Ann Surg. 2016;263(1):28-35.
7 Brenkman HJF, Gisbertz SS, Slaman AE, Goense L, Ruurda JP, Van Berge Henegouwen MI, et al. Postoperative outcomes of minimally invasive gastrectomy versus open gastrectomy during the early introduction of minimally invasive gastrectomy in the Netherlands: a population-based cohort study. Ann Surg. 2017;266(5):831-8.

8 De Vogelaere K, Van Loo I, Peters O, Hoorens A, Haentjens P, Delvaux G. Laparoscopic resection of gastric gastrointestinal stromal tumors (GIST) is safe and effective, irrespective of tumor size. Surg Endosc. 2012;26(8):2339-45.

9 Chen QL, Pan Y, Cai JQ, Wu D, Chen K, Mou YP. Laparoscopic versus open resection for gastric gastrointestinal stromal tumors: an updated systematic review and meta-analysis. World J Surg Oncol. 2014;12:206-13.

10 Otani Y, Furukawa T, Yoshida M, Saikawa Y, Wada $\mathrm{N}$, Ueda $\mathrm{M}$, et al. Operative indications for relatively small $(2-5 \mathrm{~cm})$ gastrointestinal stromal tumor of the stomach based on analysis of 60 operated cases. Surgery. 2006;139(4):484-92.

11 Dressler JA, Palazzo F, Berger AC, Stake S, Chaudhary A, Chojnacki KA, et al. Long-term functional outcomes of laparoscopic resection for gastric gastrointestinal stromal tumors. Surg Endosc. 2016;30(4):1592-8.

12 Haverkamp L, Brenkman HJ, Seesing MF, Gisbertz SS, van Berge Henegouwen MI, Luyer MD, et al. Laparoscopic versus open gastrectomy for gastric cancer, a multicenter prospectively randomized controlled trial (LOGICA-trial). BMC Cancer. 2015;15:556-7.

13 Fletcher CD, Berman JJ, Corless C, Gorstein F, Lasota J, Longley BJ, et al. Diagnosis of gastrointestinal stromal tumors: a consensus approach. Int J Surg Pathol. 2002;10(2):81-9.
14 Miettinen M, El-Rifai W, H L Sobin L, Lasota $\mathrm{J}$. Evaluation of malignancy and prognosis of gastrointestinal stromal tumors: a review. Hum Pathol. 2002;33(5):478-83.

15 Huang CM, Chen QF, Lin JX, Lin M, Zheng $\mathrm{CH}$, Li P, et al. Can laparoscopic surgery be applied in gastric gastrointestinal stromal tumors located in unfavorable sites? a study based on the NCCN guidelines. Medicine. 2017;96(14):e6535-8.

16 Karakousis GC, Singer S, Zheng J, Gonen M, Coit D, DeMatteo RP, et al. Laparoscopic versus open gastric resections for primary gastrointestinal stromal tumors (GISTs): a sizematched comparison. Ann Surg Oncol. 2011; 18(6):1599-605.

17 Melstrom LG, Phillips JD, Bentrem DJ, Wayne JD. Laparoscopic versus open resection of gastric gastrointestinal stromal tumors. Am J Clin Oncol. 2012;35(5):451-4.

18 Xiong Z, Wan W, Zeng X, Liu W, Wang T, Zhang R, et al. Laparoscopic versus open surgery for gastric gastrointestinal stromal tumors: a propensity score matching analysis. J Gastrointest Surg. 2019.

19 Bischof DA, Kim Y, Dodson R, Carolina Jimenez M, Behman R, Cocieru A, et al. Open versus minimally invasive resection of gastric gist: a multi-institutional analysis of shortand long-term outcomes. Ann Surg Oncol. 2014;21(9):2941-8.

20 Masoni L, Gentili I, Maglio R, Meucci M, D’Ambra G, Di Giulio E, et al. Laparoscopic resection of large gastric GISTs: feasibility and long-term results. Surg Endosc. 2014; 28(10):2905-10. 